\title{
INTERNATIONAL JOURNAL OF AUTOMOTIVE SCIENCE AND TECHNOLOGY
}

\section{Crash Analysis and Size Optimization of a Vehicle's Front Bumper System}

\author{
Muhammed Talha Aşkar ${ }^{*}$ and Kemal Ermiş² \\ 0000-0003-3625-024X $\mathrm{X}^{1}, 0000-0003-3110-2731^{2}$
}

${ }^{1}$ Institute of Natural Sciences, Automotive Engineering, Sakarya University, Sakarya, 54187, Turkey

${ }^{2}$ Department of Mechanical Engineering, Sakarya University of Applied Sciences, Sakarya, 54187, Turkey

\section{Abstract}

Bumper beams and crash boxes are structural vehicle elements that have very critical functions during frontal collisions. This study examined the energy absorbed by the front bumper system and the reaction forces to the cage structure representing the vehicle cabin frame during a full frontal crash against a rigid wall. For this purpose, 25 different crash analyses were conducted using the ANSYS software by changing the sheet thickness values of the bumper beam $\left(\mathrm{t}_{1}\right)$ and crash boxes-frontal crash rails $\left(\mathrm{t}_{2}\right)$ that make up the front bumper system. The internal energy (absorbed energy) of the front bumper elements from the analysis results and the reaction forces acting on the representative cage structure in the opposite direction to the movement were examined. When the obtained data were interpreted according to variable thickness, it was observed that the variable $t_{2}$ significantly affected both the absorbed energy and reaction force results, while the variable $t_{1}$ did not have a significant effect on the results. Based on this, the thickness value $t_{2}$ was determined as the design variable of the size optimization problem. When the optimization problem established with the reaction force and absorbed energy constraint functions was solved, the optimal $t_{2}$ thickness value with the highest absorbed energy / peak reaction force ratio was found.

Keywords: Bumper beam, Crash box, Energy absorption, Finite element analysis, Frontal impact, Reaction force, Size optimization

\section{Introduction}

Despite their productive, economic, and social benefits, the use of vehicles results in an array of negative repercussions such as traffic intensity, countries' dependence on petroleum products, traffic accidents, and emissions to the atmosphere. The most important of these adversities is undoubtedly traffic accidents, which has been the subject of a large body of vehicle safety research aimed to minimize casualties or injuries caused by these accidents. Vehicle safety is divided into two main groups: passive safety systems and active safety systems. Active safety systems include all sub-safety systems (ABS -antilock brake system-, ESP -electronic stability program-, AEB -autonomous emergency braking-, ACC -adaptive cruise control- etc.) that become active in the event of a possible accident, with the goal being to prevent the accident or alert the driver. The passive safety systems include all safety elements (seat belts, airbags, crash boxes, etc.) that aim to ensure the safety of the driver and passengers and/or minimize injuries in the event of an accident. The bumper system, which is the subject of this study, is part of the passive safety system. As seen in Figure 1, frontal collisions are the most common type of vehicle accident [1].

\section{Research Article}

https://doi.org/10.30939/ijastech..930944

$\begin{array}{ll}\text { Received } & 01.05 .2021 \\ \text { Revised } & 05.06 .2021 \\ \text { Accepted } & 07.06 .2021\end{array}$

* Corresponding author

Muhammed Talha Aşkar mdtalhaskar@gmail.com

Address: Institute of Natural Sciences, Automotive Engineering, Sakarya University, Sakarya, Turkey

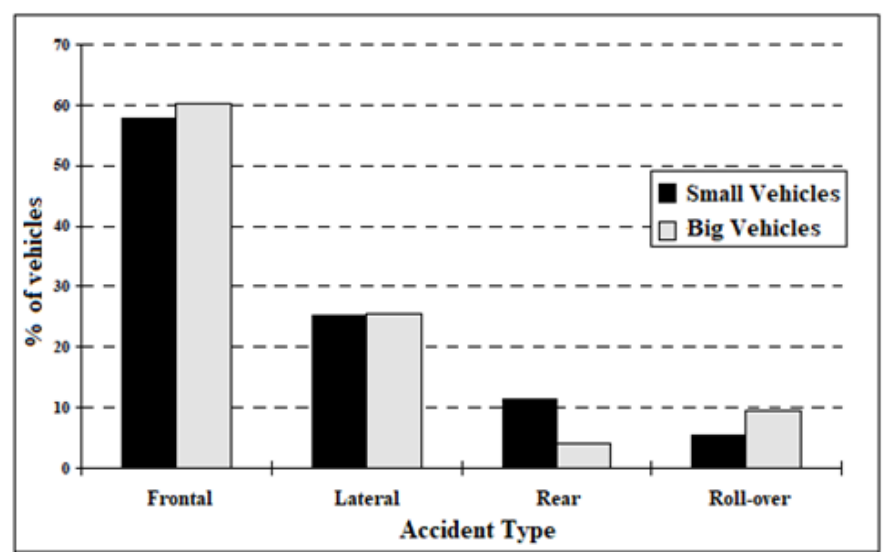

Fig. 1. Automobile collisions according to the accident [1].

Reaction forces most negatively affect the safety of the car's passengers during frontal collisions, which is the type of collision to which vehicles are most often exposed. Reducing the average reaction force to the passenger cabin and vehicle chassis during an 
accident will also mean reducing the safety risks for the driver and

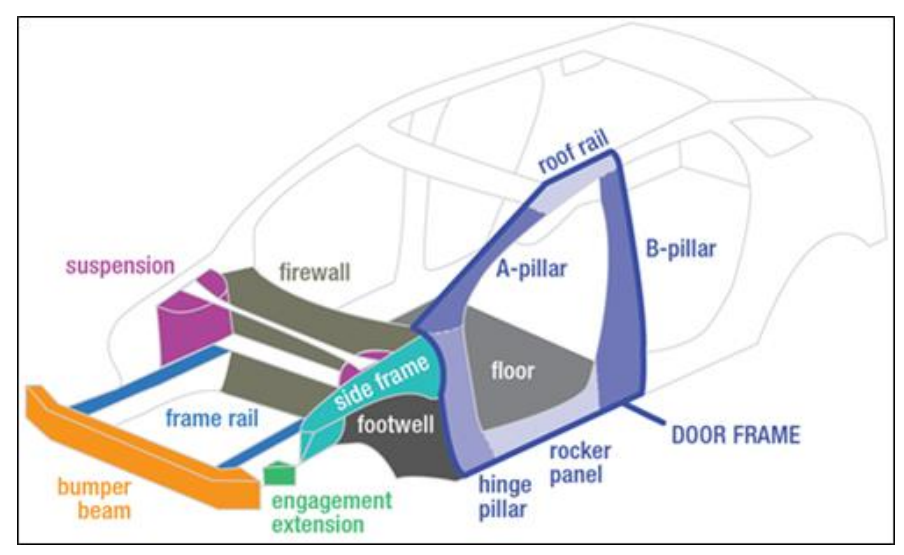

Fig. 2. Vehicle frame elements [2].

passengers. At the same time, the amount of deformation energy that reach the passenger cabin during an accident should be minimized by the front bumper elements absorbing the deformation energy as much as possible. The most important elements of the front bumper system designed for these purposes are the bumper beam and crash boxes attached to it. Elements of the vehicle frame and front bumper system [2] are shown in Fig. 2.

Impact absorbing structures in the front of the vehicle should provide a smooth deceleration acceleration for the vehicle during an accident. The vehicle body parts produced nowadays consist of high-strength profiles designed according to the space frame system and differ from the heavy parts of older bodies. The front bumper components are designed to protect the safety of the passengers' lives by significantly damping the vehicle crash forces before they reach the passenger compartment. Particularly, longitudinal impact absorbers are designed to absorb energy by deforming in an accordion form. This design depends on factors such as the cross-section of the impact absorbers, their geometry, the sheet thickness, and the type of attachment to the front bumper and chassis. This study focused on the sheet thickness factor of bumper elements.

Looking at the studies on this subject, Marzbanrad et al. in their low speed $(4 \mathrm{~km} / \mathrm{h})$ frontal collision analysis study, they examined the deflection, impact force and energy absorption results by changing the material, sheet thickness and shape of the bumper beam. When the wall thickness value was increased by 2-3-4-5 $\mathrm{mm}$, the deflection of the bumper decreased and the reaction forces increased. It was observed that the kinetic energy transferred from the impactor to the vehicle increased while the plastic strain of the bumper decreased [3].

Katkar and Bagi performed crash analyzes to examine the deflection and plastic strain results of the bumper beam at three different thicknesses (4 - 4.5 - 5mm). Deformation and plastic strain results were obtained by the full frontal impact of the rigid wall with a speed of $2.7 \mathrm{~m} / \mathrm{s}$ to the bumper model. It was observed that as the wall thickness of the bumper model increased, the maximum deformation decreased by $17 \mathrm{~mm}$ and the plastic strain decreased from $19 \%$ to $14 \%$. As a result, the stiffness of the bumper beam increased as the wall thickness increased, so the impact deformation and plastic strain values decreased [4].

Wang and $\mathrm{Li}$ aimed to improve the crash performance of the bumper beam by changing the material and thickness in their low speed $(4 \mathrm{~km} / \mathrm{h})$ impact analysis study. Full frontal impact analyzes were performed by crashing the rigid impactor to bumper system. They examined the results of the analyzes made by changing the thickness of the composite material to $5.4-6-6.6$ and $7.2 \mathrm{~mm}$. When the wall thickness of the bumper beam was reduced from $7.2 \mathrm{~mm}$ to $5.4 \mathrm{~mm}$, the maximum deformation value during the accident increased by $3 \mathrm{~mm}$, but the maximum impact acceleration at the impactor decreased by approximately $2.5 \mathrm{~m} / \mathrm{s}^{2}$ [5].

Nakazawa, Y. et al. [6] performed numerical and experimental crash analyses using the width dimension and the cross-section geometry of the crash box element as design variables, and the results were found to be compatible with each other. The new crash box developed according to the results of the analyses provided higher accident energy absorption and lightening in steel parts. Zhang, X. et al. [7] carried out experimental and numerical crash tests of twisted square section sheet tubes formed by inward folding of 1 to 4 times as an alternative to ordinary square section sheet tubes. It was observed that the results of the force response were compatible between experimental and numerical tests, and as a result, it was observed that the square sheet tubes obtained by inward bending, compared to ordinary square tubes, produced a higher average reaction force as the number of folds increased. Costas, M. et al. [8] created four different alternatives by filling the steel crash boxes with GFRP (glass fiber added), CFRP (carbon fiber added) composite polymers, PET foam, and cork stopper materials in order to increase the accident resistance of the crash boxes. When numerical and experimental crash analyses of these crash boxes were carried out, the crash box filled with CFRP (carbon fiber added polymer) achieved the best reaction force and absorbed energy results. However, the PET foam-filled crash box with the values closest to these results was determined to be the most efficient crash box when production costs were also considered.

Öztürk İ. [9] in his study, in order to determine the bumper design that will result in the highest SEA (specific energy absorption) and an acceptable PCF (peak crushing force) performed frontal collision analyzes using 1,2 and $3 \mathrm{~mm}$ sheet thickness values and AA6061-T6, AA2024-T351 and DP800 sheet metal materials (3 homogeneous and 6 combined types). The crash analyses were performed by hitting the $1500 \mathrm{~kg}$ weight rigid wall to the fixed vehicle finite element model at a speed of $50 \mathrm{~km} / \mathrm{h}$ in accordance with the Euro NCAP full width frontal impact test standards. When the collision analysis results of a total of 27 different bumper models were evaluated, it was observed that the optimal bumper design with an average PCF (peak crushing force) $(760.99 \mathrm{kN})$ and the highest SEA (specific energy absorption) results $(4.45 \mathrm{~kJ} / \mathrm{kg}$ ) was the "Center portion AA2024-T351 and side portion AA6061-T6 hybrid beam" model with sheet thicknesses of $1 \mathrm{~mm}$. In conclusion, it was stated that the determined optimal hybrid aluminum bumper model can be used in automobile front bumper design to improve crashworthiness performance. 


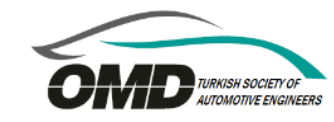

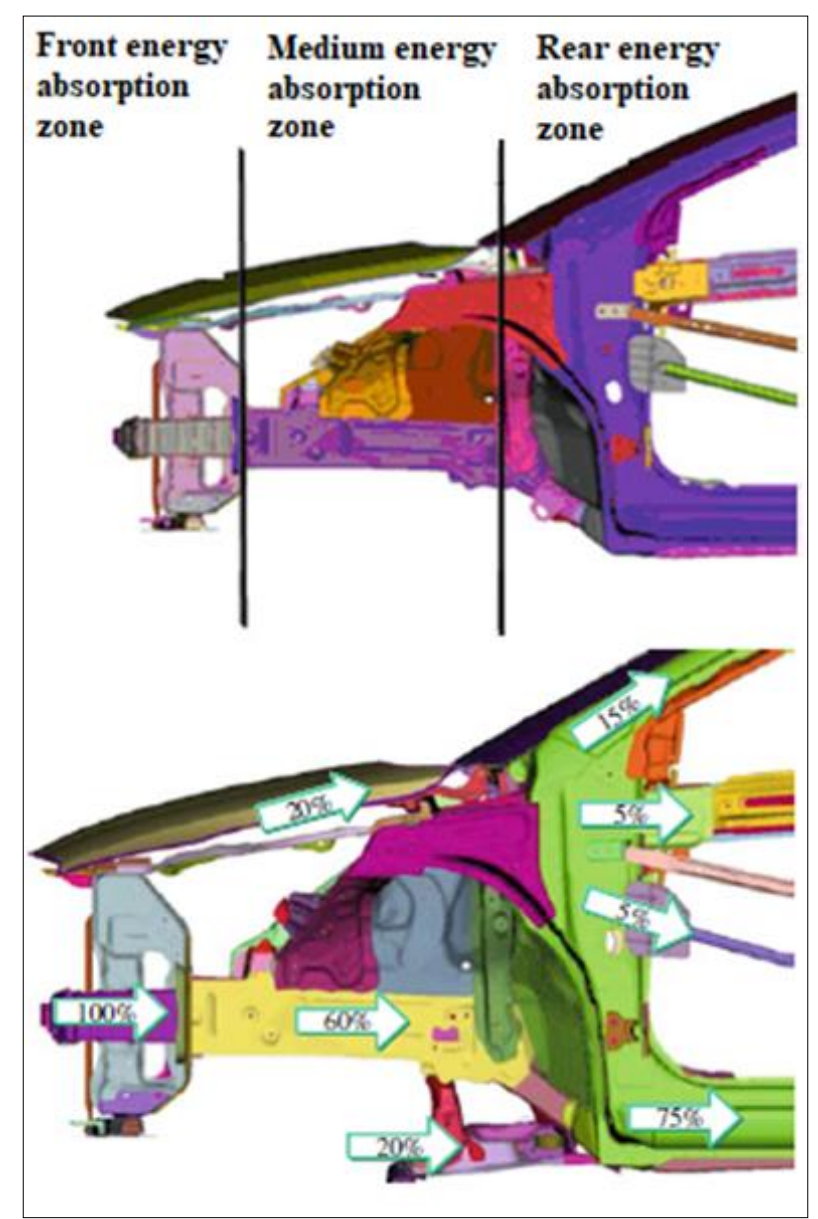

Fig. 3. Energy absorbing areas and force distribution rates in front of the vehicle [10].

As shown in Figure 3, considering the regions that absorb the impact energy to the front of the vehicle and the force distribution rates on the vehicle parts, the highest force flow (60\%) occurs over the bumper beam - crash boxes - frontal crash rails [10]. This clearly shows that the bumper system elements are extremely critical structures in the event of an accident.

Bilbay F. et al. [11] carried out crash analysis simulations to compare the effects of frontal collision rail on vehicle crash performance using FEE340 and DP600 steel materials. In the finite element analysis, they prepared using Hypermesh and Abaqus software, they crashed the $1000 \mathrm{~kg}$ defined rigid wall with a speed of $64 \mathrm{~km} / \mathrm{h}$ into the front bumper system with $100 \%$ offset. According to results of the analyses, although the CFE (crush force efficiency) results for both materials are close, it was observed that the force transmitted to the passenger cabin was 32\% lower and the crush displacement $11 \%$ higher when using the FEE340 material.

Özel S. et. al. [12] conducted crash analyses of bumper beams with 5 different cross-section geometries, to which they added hollows to reduce crash peak forces. Crash analyses was carried out by hitting $1225 \mathrm{~kg}$ weight defined bumper beam separately to the rigid wall and pole at $56 \mathrm{~km} / \mathrm{h}$. Looking at the results obtained, it

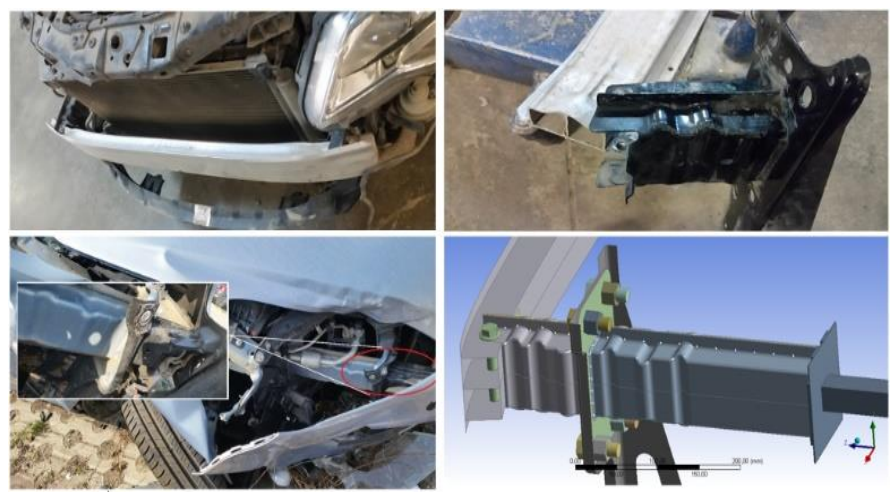

Fig. 4. Images and geometric model of the bumper beam, crash box and crash rail.

was concluded that the changes made in the bumper geometry significantly affect the crashworthiness and the hollows added to the bumpers reduce the reaction forces at the beginning of the crash.

Wagström, L. et al. [13] conducted a full-scale FEM (finite element model) of a small passenger vehicle at speeds of $32 \mathrm{~km} / \mathrm{h}$ and $56 \mathrm{~km} / \mathrm{h}$, with full and $40 \%$ offset rigid wall impact analyses using the LS-DYNA software. In the results of the analyses, it was found that when the relative energy absorption of various elements in the front of the vehicle such as the bumper beam, radiator, bonnet, longitudinal rails, and the engine was removed, the element with the highest energy absorption ratio for both speeds and impact types was the longitudinal rails that are connected to the bumper beam from the frame. Zeng, F. et al. [14] carried out accident simulations of the full-scale vehicle FEM that they obtained from NCAC (National Crash Analysis Center). It was observed that there was a general agreement between the simulation results and the acceleration-time and force-displacement curves taken from NCAP (New Car Assessment Program) tests. Then, as an alternative to the normally used steel front bumper beam, FOA (fruit fly optimization algorithm) was applied by using the beam material, composite support plate material, and the edge thickness of the beam as the design variables. When the results obtained from the optimization performed using such a combined design method were compared with the FEM simulation results of the original bumper system, $6.37 \%$ reduction in HIC (head injury criterion), $4.84 \%$ reduction in part weights, and $36 \%$ increase in energy absorption values were achieved. Li, Z. et al. [15] performed an impact analysis, against a rigid wall at $20 \mathrm{~km} / \mathrm{h}$, on the bumper assembly model, which consisted of bumper beams, crash boxes, and front rails, using the LS_DYNA program. In their study, they optimized multi-material models using AA6060, TRIP800, and DP800 bumper materials and aluminum foam filling material. As a result of the optimization of the one-material (mild steel) model, an average of $11 \%$ improvement in weight reduction, energy absorption, and peak impact strength values were achieved. Better results were obtained in the optimization of the multiple-material models using alternative materials and aluminum filler foam. 


\section{Generating FEM of the bumper system}

The flow distribution of the reaction force generated on a vehicle at the time of a frontal impact is the highest on the front bumper elements, as seen in Figure 3.

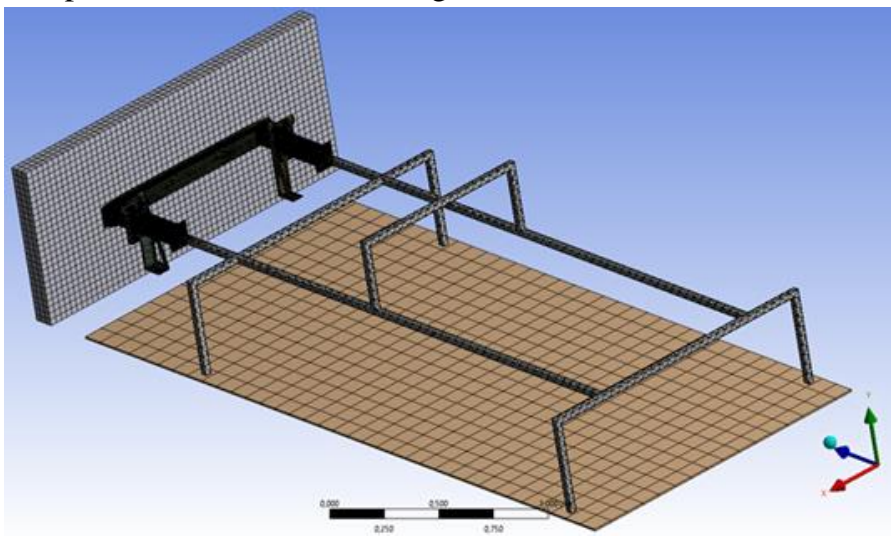

Fig. 5. FEM of the front bumper system.

In this study, full-scale 3D models of a bumper beam, crash boxes (brackets), and frontal crash rails, which constitute the front bumper system of a vehicle and which are connected to one another, was made. Images of the modeled bumper beam, crash box, and crash rail along with the $3 \mathrm{D}$ assembly model are given in Figure 4.

The geometric model of the front bumper system and the cage structure of the vehicle, the rigid wall, and the floor, which are elements of the impact analysis model, were transferred to ANSYS's Explicit Dynamics analysis module, and then finite element modeling was started.

The finite element model of the system ready for analysis was designed by following these steps:

- The whole system, with a total of 38 geometric elements including 23 solid bodies, such as bolts, nuts, floor, wall and vehicle cage, and front bumper elements with 15 surface bodies, were transferred to the analysis module.

- It was necessary to assign the materials to the relevant parts of the assembled system transferred to the analysis module. Consistent with the real materials, aluminum to the bumper beam, steel to the other bumper parts, and concrete material to the wall-floor pair were assigned.

- The Johnson-Cook material model was defined in aluminum and steel materials used in the bumper structures that would be subject to impact. This material model was a composite material model created to explain complex material behaviors such as ductile damage and plastic material flow in structural impact and penetration events and is compatible with the high strain rate deformations of most metal materials [16].

- In order for the analytical solutions of the system to take place properly and to obtain correct results, geometric elements must be divided into finite elements in types and sizes suitable for analysis. For this, the bumper beam, crash box and crash rails, which will deform in the bumper elements, were divided into rectangular surface elements; bolts and cage structure, which are rigid bodies, are divided into triangular elements, with a total of 81 thousand elements.

- As the mesh sizes of the finite element model get smaller, the total number of meshes increases and the analysis results become more sensitive. But at the same time, the solution time of the analysis becomes longer. As such, an optimum mesh size should be determined so as to give sufficiently accurate results and not unnecessarily increase the number of mesh elements. In this study, mesh element dimensions of the finite element model were determined by considering these conditions.

- As the boundary conditions of the analysis, the initial velocity of the bumper elements was $17.8 \mathrm{~m} / \mathrm{s}$; and the vehicle weight force of $11180 \mathrm{~N}$, which was acting on the middle bridge of the cage structure representing the vehicle cabin frame, the wall and floor fixed, and the rigidity of the cage structure were defined.

- An analysis solution time of $15 \mathrm{~ms}$ was determined.

- The static and dynamic friction coefficients between the bumper elements, wall and floor bodies made of aluminum, steel and concrete were defined in accordance with the data in the literature.

- Before starting the analysis solution, the results desired at the end of the solution such as internal energy, reaction force, kinetic energy, plastic work, average speed for the bumper elements, and the cage were specified in the program.

The FEM of the entire system consisting of front bumper elements, cage structure, wall, and the floor is shown in Figure 5.

\section{Results of frontal impact analyses}

With the FEM analysis created by following the steps mentioned in the previous section, 25 impact analyses prepared with different thickness combinations of the front bumper system elements were carried out in order to find the sheet thickness values where the absorbed impact energy is maximum and peak reaction force generated is minimum. The most commonly used sheet thickness values in the practice are in the range of 1 to $3 \mathrm{~mm}$. In order to make a precise comparison within these thickness values, a range of 1-2 mm has been determined to be analyzed as much as computer hardware makes possible. Bumper beam sheet thickness $\left(\mathrm{t}_{1}\right)$ values, ranging from $1.6 \mathrm{~mm}$ to $2 \mathrm{~mm}$, and crash box and crash rail thickness $\left(\mathrm{t}_{2}\right)$ values, ranging from $1.1 \mathrm{~mm}$ to $1.5 \mathrm{~mm}$, were used as analysis variables. A total of 25 analyses created in this way were solved and the results were obtained. As an example, one of the 25 analyses' deformation images of the front bumper elements at the end of the $\mathrm{t}_{1}=2 \mathrm{~mm}, \mathrm{t}_{2}=1.5 \mathrm{~mm}$ combination analysis is shown in Figure 6. 
- When evaluating the average values of the results, as seen in Table 2, the thickness of $\mathrm{t} 2$ had a significant effect on both the absorbed energy and the reaction force results; while, as seen in Table 1, the thickness of $\mathrm{t} 1$ had little effect on the absorbed energy and reaction force results.

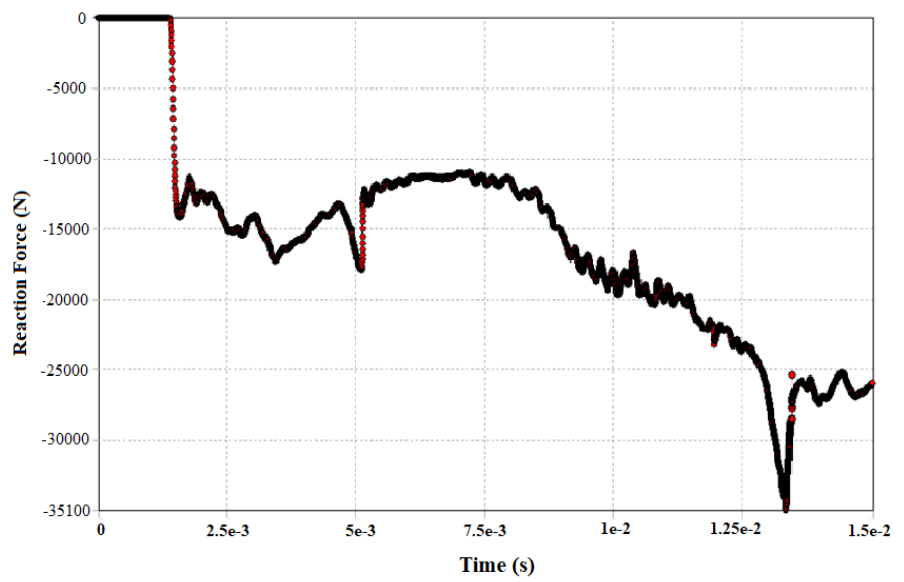

Fig. 8. Change of reaction force acting on the cage structure in the $-\mathrm{Z}$ direction for the bumper system with $\mathrm{t}_{1}=2 \mathrm{~mm}$ and $\mathrm{t}_{2}=1.5 \mathrm{~mm}$ tickness.

Table 1. Results of absorbed energy and peak reaction force and averages of results ( $t_{1}$ constant).

\begin{tabular}{|c|c|c|c|c|c|}
\hline $\mathrm{t}_{1}(\mathrm{~mm})$ & $\mathrm{t}_{2}(\mathrm{~mm})$ & $\mathrm{E}(\mathrm{kJ})$ & $\mathrm{F}_{\max }(\mathrm{kN})$ & $\mathrm{E}_{\mathrm{avg}}(\mathrm{kJ})$ & $\mathrm{F}_{\text {avg }}(\mathrm{kN})$ \\
\hline \multirow{5}{*}{1.6} & 1.1 & 31.5 & 9.5 & \multirow{5}{*}{37.5} & \multirow{5}{*}{14.06} \\
\hline & 1.2 & 34 & 10.3 & & \\
\hline & 1.3 & 38 & 11.7 & & \\
\hline & 1.4 & 40.2 & 14.8 & & \\
\hline & 1.5 & 43.8 & 24 & & \\
\hline \multirow{5}{*}{1.7} & 1.1 & 31.5 & 9.2 & \multirow{5}{*}{38.2} & \multirow{5}{*}{13.6} \\
\hline & 1.2 & 34.4 & 10.4 & & \\
\hline & 1.3 & 38.5 & 11.3 & & \\
\hline & 1.4 & 42.2 & 13.8 & & \\
\hline & 1.5 & 44.5 & 23.3 & & \\
\hline \multirow{5}{*}{1.8} & 1.1 & 30.8 & 8.2 & \multirow{5}{*}{37.5} & \multirow{5}{*}{13.2} \\
\hline & 1.2 & 34.9 & 10.8 & & \\
\hline & 1.3 & 38.1 & 11.6 & & \\
\hline & 1.4 & 40.4 & 13.4 & & \\
\hline & 1.5 & 43.4 & 22 & & \\
\hline \multirow{5}{*}{1.9} & 1.1 & 31.8 & 8.6 & \multirow{5}{*}{40.0} & \multirow{5}{*}{14} \\
\hline & 1.2 & 36.9 & 10 & & \\
\hline & 1.3 & 41.7 & 12.8 & & \\
\hline & 1.4 & 43.6 & 14.4 & & \\
\hline & 1.5 & 46.0 & 24.2 & & \\
\hline \multirow{5}{*}{2} & 1.1 & 32.6 & 8.4 & \multirow{5}{*}{40.5} & \multirow{5}{*}{16.84} \\
\hline & 1.2 & 36.9 & 10.3 & & \\
\hline & 1.3 & 41.3 & 13.7 & & \\
\hline & 1.4 & 44.4 & 16.7 & & \\
\hline & 1.5 & 47.1 & 35.1 & & \\
\hline
\end{tabular}


Graphed 3D results are given in Figure 9 to visually examine the changes in the energy absorbed by the bumper system.

Table 2. Results of absorbed energy and peak reaction force and averages of results ( $\mathrm{t}_{2}$ constant)

\begin{tabular}{|c|c|c|c|c|c|}
\hline $\mathrm{t}_{1}(\mathrm{~mm})$ & $\mathrm{t}_{2}(\mathrm{~mm})$ & $\mathrm{E}(\mathrm{kJ})$ & $\mathrm{F}_{\max }(\mathrm{kN})$ & $\mathrm{E}_{\text {avg }}(\mathrm{kJ})$ & $\mathrm{F}_{\text {avg }}(\mathrm{kN})$ \\
\hline 1.6 & \multirow{5}{*}{1.1} & 31.5 & 9.5 & \multirow{5}{*}{31.64} & \multirow{5}{*}{8.78} \\
\hline 1.7 & & 31.5 & 9.2 & & \\
\hline 1.8 & & 30.8 & 8.2 & & \\
\hline 1.9 & & 31.8 & 8.6 & & \\
\hline 2 & & 32.6 & 8.4 & & \\
\hline 1.6 & \multirow{5}{*}{1.2} & 34 & 10.3 & \multirow{5}{*}{35.4} & \multirow{5}{*}{10.36} \\
\hline 1.7 & & 34.4 & 10.4 & & \\
\hline 1.8 & & 34.9 & 10.8 & & \\
\hline 1.9 & & 36.9 & 10 & & \\
\hline 2 & & 36.9 & 10.3 & & \\
\hline 1.6 & \multirow{5}{*}{1.3} & 38 & 11.7 & \multirow{5}{*}{39.5} & \multirow{5}{*}{12.22} \\
\hline 1.7 & & 38.5 & 11.3 & & \\
\hline 1.8 & & 38.1 & 11.6 & & \\
\hline 1.9 & & 41.7 & 12.8 & & \\
\hline 2 & & 41.3 & 13.7 & & \\
\hline 1.6 & \multirow{5}{*}{1.4} & 40.2 & 14.8 & \multirow{5}{*}{42.2} & \multirow{5}{*}{14.62} \\
\hline 1.7 & & 42.2 & 13.8 & & \\
\hline 1.8 & & 40.4 & 13.4 & & \\
\hline 1.9 & & 43.6 & 14.4 & & \\
\hline 2 & & 44.4 & 16.7 & & \\
\hline 1.6 & \multirow{5}{*}{1.5} & 43.8 & 24 & \multirow{5}{*}{45.0} & \multirow{5}{*}{25.72} \\
\hline 1.7 & & 44.5 & 23.3 & & \\
\hline 1.8 & & 43.4 & 22 & & \\
\hline 1.9 & & 46.0 & 24.2 & & \\
\hline 2 & & 47.1 & 35.1 & & \\
\hline
\end{tabular}

$\square 30-32 \square 32-34 \square 34-36 \square 36-38 \square 38-40 \square 40-42 \square 42-44 \square 44-46 \square 46-48$

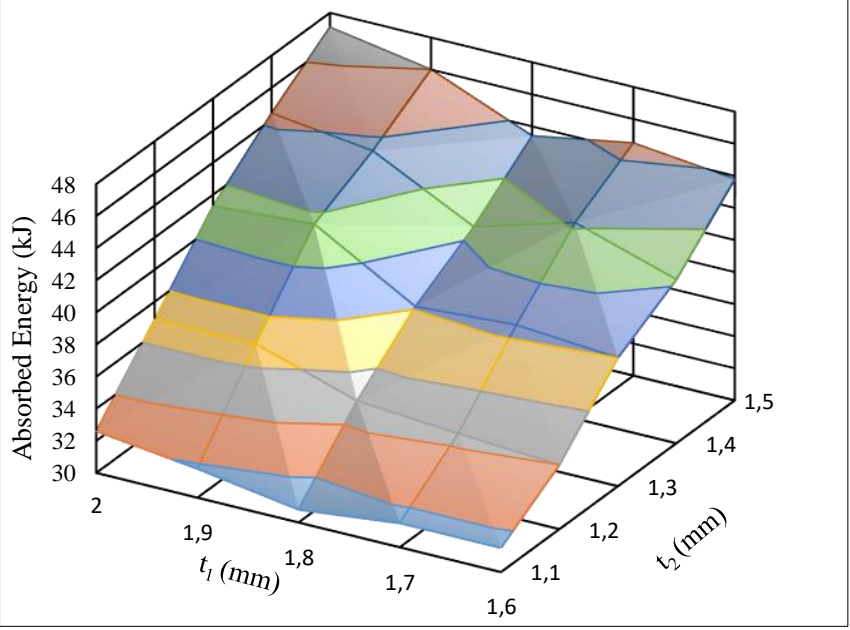

Fig. 9. Graph of energy absorbed by front bumper elements according to $t_{1}$ and $t_{2}$ thickness
Graphed 3D results are given in Figure 10 to visually examine the changes in the results of the peak reaction force acting on the cage structure.

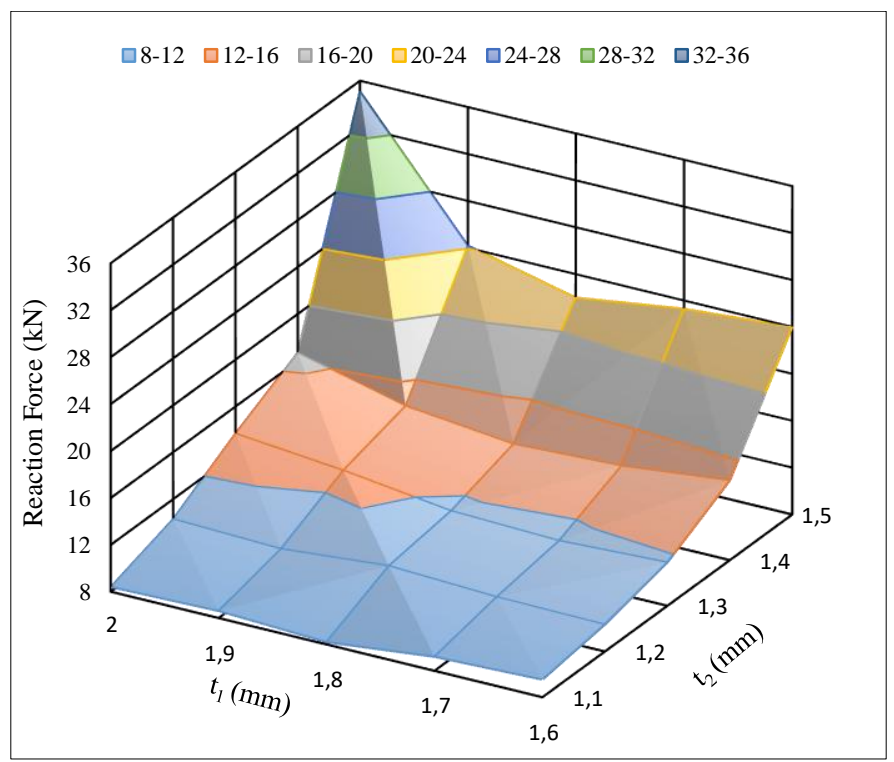

Fig. 10. Graph of peak reaction forces acting on the cage structure in the $-\mathrm{Z}$ direction according to $\mathrm{t}_{1}$ and $\mathrm{t}_{2}$ thickness.

\section{Size optimization}

When designing products in the automotive industry, optimization is an important step in the product life cycle and cost values. Since the total life cycle cost of the products is determined at the design stage, the aim is to obtain the optimal product that meets the desired criteria during this stage [17].

Optimization is the process of finding the optimal value by determining design variables, objective and constraint functions (if any) by obtaining mathematical programming (definition) after acquiring the analysis data results of a problem.

In general, the mathematical definition of an optimization problem is as follows:

Objective function, $\mathrm{f}(\mathrm{x})$, is defined Eq. (1):

$f(x) \quad x=\left(x_{1}, x_{2}, \ldots, x_{n}\right)$

where $x$ denotes design variables, $\mathrm{f}(\mathrm{x})$ is the objective function.

Constraint functions, $\mathrm{g}_{\mathrm{j}}(\mathrm{x})$ and $\mathrm{h}_{\mathrm{k}}(\mathrm{x})$ are defined Eq. (2):

$$
\begin{array}{ll}
g_{j}(x) \leq 0 & j=1, \ldots, m \\
h_{k}(x)=0 & k=1, \ldots, p
\end{array}
$$

where $x$ denotes design variables, $\mathrm{g}(\mathrm{x})$ is the inequality constraint function, and $\mathrm{h}(\mathrm{x})$ is the equality constraint function.

As stated in the evaluation of the result tables in the previous section, the $t_{1}$ parameter has little effect on the results, while the $t_{2}$ parameter has a significant effect on the results. Hence, $\mathrm{t}_{2}$ was determined as the design variable of optimization. The results of the $\mathrm{t}_{1}=1.8 \mathrm{~mm}$ thickness analysis with the lowest average force value $(13.2 \mathrm{kN})$ were chosen as the data series to be used in optimization due to the vital effect of the reaction forces on the passengers during a collision. The objective function is based on finding the maximum value of absorbed energy/peak reaction force ratios of these 
results; the constraint functions are defined according to the peak reaction force and absorbed energy data. The coefficients of determination $\left(\mathrm{R}^{2}\right)$ of the objective and constraint equations are 1 . Since all identical structural elements of the vehicle was not analyzed, the limit values of the constraint functions were arbitrarily chosen from Table 1 and the average reaction force value and the average energy absorption value were taken as $13.2 \mathrm{kN}$ and $37.5 \mathrm{~kJ}$.

Identification of the optimization problem

The design variable is made under $\mathrm{t}_{2}=\mathrm{x}$ and $1.1 \leq \mathrm{x} \leq 1.5 \mathrm{~mm}$ boundary conditions.

The objective function is defined by the absorbed energy divided by the maximum reaction force as shown in Eq. (3).

$$
\begin{aligned}
E / F_{\max }= & 187.53 \mathrm{x}^{4}-1087.67 \mathrm{x}^{3}-2322.38 \mathrm{x}^{2} \\
& -2171.65 \mathrm{x}+755.62
\end{aligned}
$$

Constraint functions are defined according to the minimum limit of absorbed energy and maximum limit of reaction force as shown in Eq.(4) and Eq.(5).

$$
\begin{gathered}
E(x)=666.67 \mathrm{x}^{4}-3333.3 \mathrm{x}^{3}+6188 \mathrm{x}^{2} \\
-5022.2 \mathrm{x}+1527.9 \geq 37.5 k J \\
F_{\max }(x)=1250 \mathrm{x}^{4}-5783.3 \mathrm{x}^{3}+9917.5 \mathrm{x}^{2} \\
-7443.2 \mathrm{x}+2063 \leq 13.2 k N
\end{gathered}
$$

The optimization problem defined as such is solved by the fmincon constrained nonlinear minimization tool, one of the optimization solvers of the MATLAB program. The $t_{2}$ thickness with the highest $\mathrm{E} / \mathrm{F}_{\max }$ ratio (3.28) was found to be $1.3 \mathrm{~mm}$ under these constraints. Thus, while remaining below the maximum force limit and above the minimum absorbed energy limit, the optimal crash box-crash rail sheet thickness value with the highest $\mathrm{E} / \mathrm{F}_{\max }$ ratio was found.

\section{Conclusions}

In this study, the metal elements of an automobile front bumper and a cage structure representing the vehicle frame were modeled in 3D and a full frontal crash analysis against a rigid wall at a speed of $64 \mathrm{~km} / \mathrm{h}(17.8 \mathrm{~m} / \mathrm{s})$ was performed in the Explicit Dynamics module of the ANSYS finite element analysis program.

In the event of a frontal impact, the effect of the sheet thickness values of the front bumper elements on the energy absorbed by the vehicle's front bumper system and the reaction force reaching the passenger cabin was examined. In order to find the optimal sheet thickness values that provide the best results, 25 analyses were performed. When the analysis results obtained were interpreted, it was observed that the thickness of the bumper beam sheet $t_{1}$ had little effect on the results and the data result of the analysis (5 pieces) with the lowest response force average $t_{1}=1.8 \mathrm{~mm}$ was selected for optimization. The optimum $t_{2}$ thickness value with the highest absorbed energy/reaction force ratio, which was within the limit values of minimum absorbed energy and maximum response force determined using the results, was found to be $1.3 \mathrm{~mm}$. Findings and inferences from this study are as follows:
- The most critical components in the current vehicle bumper system that require engineering design and analysis are crash boxes and crash rails.

- A numerical analysis of the front bumper system, designed to generate as little reaction force as possible in the passenger cabin and to provide the most energy absorption by the front bumper elements during a collision, must be carried out together with a reference experimental analysis and the system must be optimized to meet these requirements.

- The reaction forces and energy absorbed increase with the increase of the sheet thicknesses of the bumper elements. For this reason, it is an important step in these studies to find the optimal thickness values of the bumper system elements by performing an optimization based on the desired boundary conditions and analysis data.

- It was observed that changing the sheet thickness of the bumper beam has no significant effect on the reaction force and absorbed energy results.

- It was observed that changing the sheet thickness of the crash boxes and the impact absorbing frontal crash rails have a significant effect on the results; for this reason, the sheet thickness of these parts was used as a design variable in the optimization process.

- In terms of checking the reliability of the analysis results and to ensure that the optimization process is applied according to the most accurate data results, if the impact simulation of the entire vehicle or partial structural elements is carried out together with an experimental test, possible errors can be determined and analysis study can be verified.

- In the finite element analysis, the more details and finite element number of 3D model are inputted, the more processor capacity is required for the solution of the analysis. Therefore, in order to perform more realistic analyses and obtain more accurate results, high capacity processors are needed to be able to analyze the FEM of the entire body structures of a vehicle and get faster solutions.

In future studies, the following can be done to improve the crash performance of bumper systems:

- A certain number of crash analyzes can be performed by changing the wall thickness of the bumper elements in the range of 1 to $3 \mathrm{~mm}$. Optimization can be made using the data of peak response force and total absorbed energy results obtained from these analyzes, and thus sheet thickness values that exhibit superior impact behavior for a wider thickness range can be determined.

- For certain wall thickness values, the dimensions, geometry and number of groves in the crash box and crash rail can be parameterized separately. If the results of crash analyzes using these parameters are optimized, grove configurations with better results can be achieved.

- The material of bumper beam, crash box and crash rail can also be parameterized at certain wall thickness values. Superior crash performance results can be achieved by using steel, aluminum alloy, composite, elastoplastic and foam materials as single and hybrids. 


\section{Nomenclature}

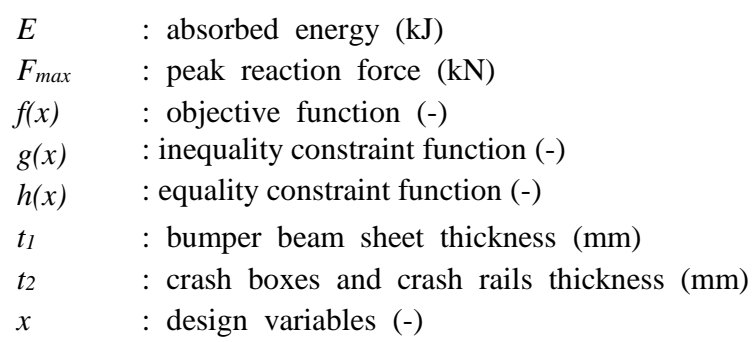

\section{Conflict of Interest Statement}

The authors declare that there is no conflict of interest.

\section{CRediT Author Statement}

Muhammed Talha Aşkar: Conceptualization, Investigation, Formal analysis, Methodology, Visualization, Writing-original draft, Writing-review\&editing,

Kemal Ermiş: Data curation, Writing-review \& editing

\section{References}

[1] Thomas P, Frampton R. Large and Small Cars in Real-World Crashes -Patterns of Use, Collision Types and Injury Outcomes, 43rd Annual Meeting of the Association for the Advancement of Automotive Medicine. Barcelona, 1999;43:101-118.

[2] Status Report newsletter, Insurance Institute for Highway Safety IIHS. 2014;49, No. 11:1-4.

[3] Marzbanrad J, Alijanpour M, Kiasat MS. Design and analysis of anautomotive bumper beam in low-speed frontal crashes. ThinWalled Structures. 2009;47:902-911.

[4] Katkar AD, Bagi JS. Bumper design enhancement through crash analysis. International Journal of Engineering Technology, Management and Applied Sciences. 2015;3:272-279

[5] Wang T, Li Y. Design and analysis of automotive carbon fiber composite bumper beam based on finite element analysis. Advances in Mechanical Engineering. 2015;7(6):1-12

[6] Nakazawa Y, Tamura K, Yoshida M, Takagi K, Kano M. Development of crash-box for passenger car with high capability for energy absorption. VIII. International Conference on Computational Plasticity. Barcelona, 2005:1-4.

[7] Zhang X, Zhang H, Ren W. Axial crushing of tubes fabricated by metal sheet bending. Thin-Walled Structures. Elsevier Ltd; 2018; 122:252-263.

[8] Costas M, Díaz J, Romera LE, Hernández S, Tielas A. Static and dynamic axial crushing analysis of car frontal impact hybrid absorbers. International Journal of Impact Engineering. Pergamon; 2013;62:166-181.

[9] Öztürk İ. Design and optimisation of hybrid material bumper beams under impact loading. International Journal of Crashworthiness. Taylor \& Francis; 2020:1-13

[10] Shen Z, Qiao X, Chen H. BIW safety performance research based on vehicle frontal crash, Lecture Notes in Electrical Engineering. Springer Verlag; 2013:13-26.
[11] Bilbay FB, Reis M, Çakan BG, Çakır MC. Crush Performance Comparison of FEE340 and DP600 Materials as Front Collision Rail in Automobiles. Uludağ University Journal of The Faculty of Engineering. (in Turkish), 2019;24(1): 415-428.

[12] Özel S, Karagöz S, Beytüt H. Crashworthiness investigation of vehicle front bumper beam with different cross-sections under axial dynamic load. European Journal of Technique. 2020;10(1): 97-105.

[13] Wågström L, Thomson R, Pipkorn B. Structural adaptivity in frontal collisions: implications on crash pulse characteristics. International Journal of Crashworthiness. 2005;10(4):371-378.

[14] Zeng F, Xie H, Qiming L, Li F, Tan W. Design and optimization of a new composite bumper beam in high-speed frontal crashes. Structural and Multidisciplinary Optimization. 2016;53:115-122.

[15] Li Z, Yu Q, Zhao X, Yu M, Shi P, Yan C. Crashworthiness and lightweight optimization to applied multiple materials and foamfilled front end structure of auto-body. Advances in Mechanical Engineering. 2017;9(8):1-21.

[16] Memiş İ. Impact response of Ramor500 armor steel subjected to high velocities. Dokuz Eylül University, Institute of Science, Mechanical Engineering, Master's Thesis, 2016.

[17] Y1ldiz AR. Optimum design of vehicle components using structural optimization techniques. Journal of Polytechnic. 2017; 20(2):319-323. 